\title{
A Gene-for-Gene Relationship Between Wheat and Mycosphaerella graminicola, the Septoria Tritici Blotch Pathogen
}

\author{
Penny A. Brading, Els C. P. Verstappen, Gert H. J. Kema, and James K. M. Brown
}

First and fourth authors: Disease and Stress Biology Department, John Innes Centre, Norwich Research Park, Colney, Norwich, NR4 7UH, England; and second and third authors: Plant Research International BV, P.O. Box 16, 6700 AA Wageningen, The Netherlands. Current address of P. A. Brading: Wheat Improvement Centre-Syngenta, Norwich Research Park, Colney, Norwich, NR4 7UH, England. Accepted for publication 27 December 2001.

\section{ABSTRACT}

Brading, P. A., Verstappen, E. C. P., Kema, G. H. J., and Brown, J. K. M. 2002. A gene-for-gene relationship between wheat and Mycosphaerella graminicola, the Septoria tritici blotch pathogen. Phytopathology 92: 439-445.

Specific resistances to isolates of the ascomycete fungus Mycosphaerella graminicola, which causes Septoria tritici blotch of wheat, have been detected in many cultivars. Cvs. Flame and Hereward, which have specific resistance to the isolate IPO323, were crossed with the susceptible cv. Longbow. The results of tests on F1 and F2 progeny indicated that a single semidominant gene controls resistance to IPO323 in each of the resistant cultivars. This was confirmed in F3 families of Flame $\times$ Longbow, which were either homozygous resistant, homozygous susceptible, or segregating in tests with IPO323 but were uniformly susceptible to another isolate, IPO94269. None of 100 F2 progeny of Flame $\times$ Hereward were susceptible to IPO323, indicating that the resistance genes in these two cultivars are the same, closely linked, or allelic. The resistance gene in cv. Flame was mapped to the short arm of chromosome 3A using microsatellite markers and was named Stb6. Fiftynine progeny of a cross between IPO323 and IPO94269 were used in complementary genetic analysis of the pathogen to test a gene-for-gene relationship between Stb6 and the avirulence gene in IPO323. Avirulence to cvs. Flame, Hereward, Shafir, Bezostaya 1, and Vivant and the breeding line NSL92-5719 cosegregated, and the ratio of virulent to avirulent was close to 1:1, suggesting that these wheat lines may all recognize the same avirulence gene and may all have Stb6. Together, these data provide the first demonstration that isolate-specific resistance of wheat to Septoria tritici blotch follows a gene-for-gene relationship.
Septoria tritici blotch, caused by the ascomycete fungus $\mathrm{Myco}$ sphaerella graminicola (anamorph Septoria tritici), is currently the most serious foliar disease of wheat in Europe and in several other temperate and subtropical regions of the world $(17,36)$. The use of resistant cultivars reduces the requirement for costly fungicide treatments and is therefore an increasingly popular strategy for controlling Septoria tritici blotch. Consequently, wheat breeders have been selecting resistance over the last 3 decades $(15,23)$.

The genetics of resistance to Septoria tritici blotch are not well understood. Specific interactions between wheat cultivars and $M$. graminicola isolates occur in both seedling tests and under field conditions $(2,3,5,26-28)$. This raises the possibility that the specific interactions may operate through a gene-for-gene mechanism $(16,26,30)$ in which, for every gene conferring resistance in the host, there is a corresponding gene for avirulence in the pathogen (18). The operation of a gene-for-gene system implies that a resistance gene will be overcome once the pathogen acquires virulence by loss or alteration of the corresponding gene for avirulence. Specific resistance to Septoria tritici blotch has deteriorated in field situations; for example, cv. Gene became highly susceptible within 5 years of its release in Oregon (9).

The best studied of these specific interactions is that between isolate IPO323 from The Netherlands and several wheat cultivars of apparently diverse origin $(2,5,28)$. The genetics of avirulence in IPO323 have been studied in segregating progeny of a cross with IPO94269, an isolate that is virulent toward many IPO323-resistant cultivars (30). Avirulence to three IPO323-resistant cultivars cosegregated, indicating, among other possibilities, that IPO323

Corresponding author: P. A. Brading; E-mail address: penny.brading@syngenta.com

Publication no. P-2002-0220-02R

(c) 2002 The American Phytopathological Society may carry three avirulence genes in a tightly linked cluster or that a single avirulence gene is recognized by the same resistance gene present in each cultivar. These results strongly support the hypothesis that there are gene-for-gene interactions between $M$. graminicola and wheat, but formal proof of a gene-for-gene relationship requires the characterization of both the genetics of avirulence and the genetics of the matching resistance within a given interaction (18). To this end, we have investigated the genetics of specific resistance to IPO323 in cvs. Flame and Hereward and of the matching avirulences in IPO323.

In this article, we present evidence for a gene-for-gene interaction between $M$. graminicola and several wheat cultivars. In particular, we have identified a resistance gene in cvs. Flame and Hereward that corresponds to an avirulence gene in IPO323, conforming to the gene-for-gene model. We have mapped the resistance gene in cv. Flame, named Reaction to Mycosphaerella graminicola 6 (Stb6), to the short arm of chromosome 3A.

\section{MATERIALS AND METHODS}

Plant and pathogen material. Reciprocal crosses and subsequent F2 populations were made between cvs. Flame, Hereward, and Longbow. The 80 F2 seedlings from the cross between cvs. Flame and Longbow were used in detached leaf tests and were allowed to self-fertilize and generate F3 families.

Two M. graminicola isolates from the Netherlands, IPO323 (28) and IPO94269 (29), were used, as well as a subset of 59 F1 isolates of a mapping population generated by a cross between IPO323 and IPO94269 (30) (note that M. graminicola is a haploid organism, so segregation occurs in the F1 generation). Isolates were grown and adjusted to an inoculum concentration of $10^{7}$ conidia $\mathrm{ml}^{-1}$ as described previously (2).

Seedling tests. Disease tests on seedlings were done either with detached leaves or whole plants. The choice of test is largely one 
A

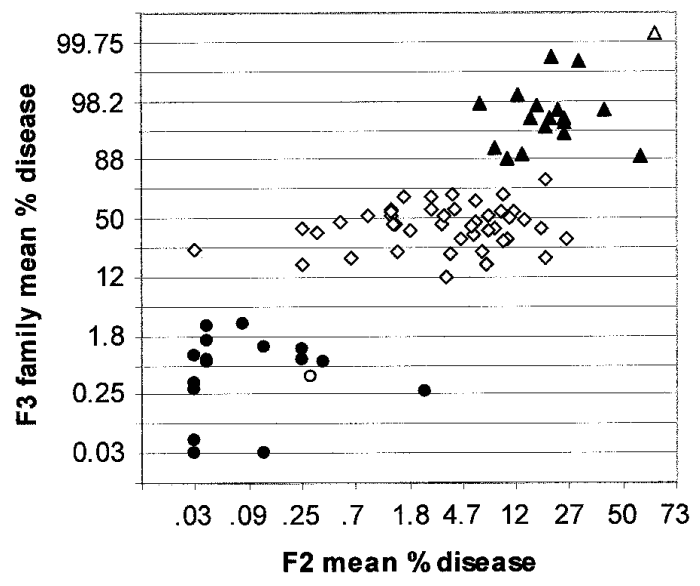

B

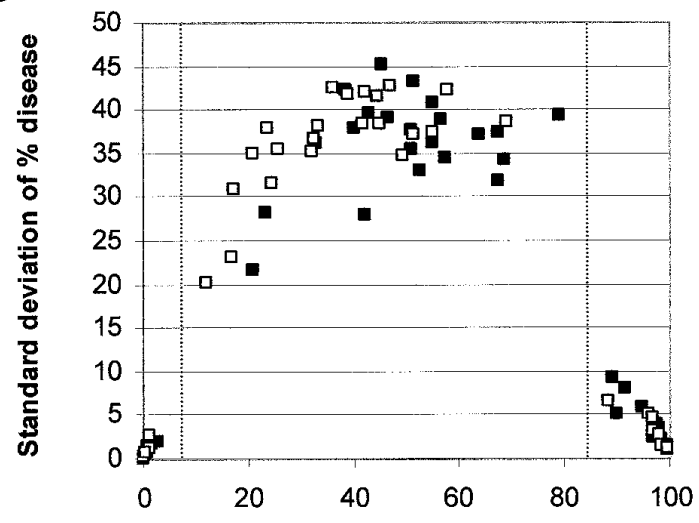

Mean \% disease in F3 families

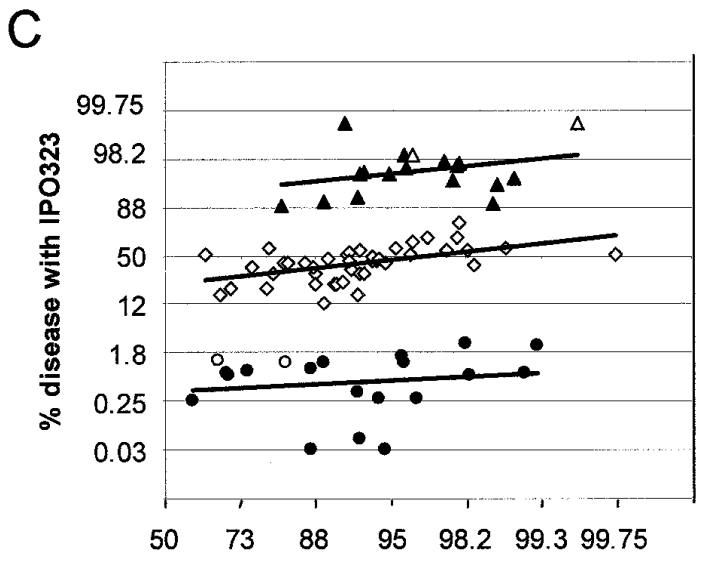

$\%$ disease with IPO94269

Fig. 1. Segregation of specific resistance to IPO323 in Flame $\times$ Longbow progeny. A, Mean percent disease levels for Flame $\times$ Longbow F3 families (whole seedlings) plotted against the means of the corresponding F2 individuals (detached leaves). F2 and F3 plants inoculated with isolate IPO323. F3 families classified as resistant (closed circles), intermediate (open diamonds), or susceptible (closed triangles), according to the groups shown in B. Open circle: Flame, open triangle: Longbow. B, Standard deviations of percent disease levels within Flame $\times$ Longbow F3 families following inoculation with IPO323, plotted against mean disease levels. Flame was the maternal crossing parent for half of the families (open squares) and the paternal parent for the other half (closed squares). The dashed lines show that the families fall into three nonoverlapping groups. C, Comparison of disease levels of the F3 families following inoculation with IPO323 and IP094269. Symbols as in $\mathbf{A}$; there were two replicates each of Flame and Longbow. For clarity in $\mathbf{A}$ and $\mathbf{C}$, the axes are logit-scaled but labeled as percentages. of convenience, as they produce similar results (2). The former is preferred when replicate observations are required from single plants and the latter when many plants need to be tested with a single isolate.

Detached seedling leaf assays were carried out by the method of Arraiano et al. (2). Four replicate leaf sections were used in tests of F1 and F2 seedlings, two from the primary leaf and two from the second leaf. Agar boxes (2) contained up to eight leaf sections, including the resistant parents of the cross and the susceptible cv. Longbow as controls. Tests were always done with progeny of each reciprocal cross in equal proportions to control for the possibility of a maternal effect. Except for the Flame $\times$ Longbow F2 test which was set up in a single day, all other detached leaf experiments were divided so that half of each generation was tested on one of two separate days. This provided experimental replication and allowed reproducibility to be assessed.

The 59 progeny of the cross IPO323 $\times$ IPO94269 were tested in four experiments, each including 15 progeny plus IPO323 and IPO94269. Each combination of cultivar and isolate was replicated four times in randomized blocks. Tests of 26 progeny were replicated in two further experiments. In all experiments, disease severity was scored several times between 15 and 28 days after inoculation. Data from all the tests were combined for statistical analysis.

Tests of the F3 generation of the Flame $\times$ Longbow cross were done on whole seedlings. Pregerminated seeds (2) were sown in 16-by-22-cm trays, each containing two F3 families. From each family, 16 seedlings were tested with IPO323 and 12 with IPO94269. Fifteen-day-old seedlings were inoculated by the same method as used for the detached leaf tests (2) and the following incubation conditions were similar to those in Kema et al. (26) with several modifications. Inoculated seedlings were allowed to dry for up to $1 \mathrm{~h}$ before being placed under clear polythenecovered incubation tents that were shaded for $48 \mathrm{~h}$ after inoculation. The seedlings were not watered during this period, but bench matting was kept wet to maintain high humidity. After $48 \mathrm{~h}$, the tents were kept under sodium lights (16-h photoperiod) and seedlings were watered from above twice daily. Second- and laterformed leaves were cut off the seedlings 1 week after inoculation and again when the primary leaves were first scored for disease. The glasshouse temperature was set to $20^{\circ} \mathrm{C}$ day and $10^{\circ} \mathrm{C}$ night.

In both detached leaf and whole seedling experiments, disease was scored as the percentage of leaf area covered by necrotic lesions bearing pycnidia. In all tests, individual leaves were scored at least twice, allowing the area under disease progress curve (AUDPC) (39) to be calculated from the combined scores. Estimates of mean AUDPC scores on the parental cultivars and progeny lines in detached leaf and whole seedling tests and standard deviations of scores of F3 families were calculated by generalized linear mixed modeling (GLMM) of binomial proportions with a logit link function (46). This method was used because disease levels were scored on a percentage scale and both random and fixed effects were involved. The variate analyzed was actual AUDPC as a proportion of the maximum possible AUDPC (max. AUDPC is calculated assuming a score of $100 \%$ for every date on which the test was scored). Data were analyzed using Genstat for Windows (4th ed., Numerical Algorithms Group Ltd., Oxford).

Field trials. $M$. graminicola isolates IPO323, IPO94269, and a subset of $57 \mathrm{~F} 1$ progeny of a cross between these isolates (30) were tested under field conditions on cvs. Shafir, Hereward, Vivant, and the breeding line NSL 92-5719, all of which are specifically resistant to IPO323 and susceptible to IPO94269 $(5,28)$. The experiments were performed in 2 years in two replicates arranged in a split-plot design. Isolates were randomized over main plots and plant lines were randomized as subplots within main plots. Shafir was used as a control to compare with seedling data obtained previously (30), because it is specifically 
resistant to IPO323 but susceptible to IPO94269. In both, years the trials were sown as hill plots and were inoculated (28) with conidial suspensions at a concentration of 1 to $1.5 \times 10^{6}$ spores per $\mathrm{ml}$. Plants were scored qualitatively three times as either resistant or susceptible to IPO323, because avirulence to the control cv. Shafir was shown previously to segregate from virulence as a discrete character in this progeny set (30). Plants were scored as susceptible if leaves were completely necrotic with an abundance of pycnidia, or as resistant if leaves had no or very limited necrosis, generally at the tips, without pycnidia (30).

DNA extraction and microsatellite mapping. Fifty-eight Flame $\times$ Longbow lines (single-seed descent to F4) that were known from F3 family tests to be homozygous for the presence or absence of Stb6 were used as a mapping population. DNA was prepared from eight 14-day-old seedlings per line using a simple cetyltrimethylammonium bromide (CTAB) extraction method based on Stewart and Via (42). DNA concentrations were estimated with a spectrophotometer (Ultrospec 2000; Amersham Pharmacia Biotech, Buckinghamshire, UK) and were adjusted to a concentration of $30 \mathrm{ng} \mu \mathrm{l}^{-1}$ for microsatellite analysis. Polymerase chain reaction amplification, polyacrylamide gel electrophoresis, and silver staining were done as described previously (6).

Microsatellite markers mapped previously to wheat chromosome 3A (WMC markers developed by an international consortium led by Agrogene SA, Moissy Cramayel, France; the remainder in Bryan et al. [6] and Röder et al. [37]) were provided by Pauline Stephenson (Comparative Genetics Unit, John Innes Centre, Norwich, UK). All aspects of genetic mapping, including formation of linkage groups and mapping markers within groups, were done using JoinMap version 2.0 (41). Recombination fractions were converted to map distances by the Kosambi (32) function.

\section{RESULTS}

Resistance of Flame to IPO323. Thirty-two F1 progeny of the cross between cvs. Flame and Longbow were inoculated with IPO323 as whole seedlings and 12 in detached leaf tests. In both cases, reciprocal crosses were used in equal proportions. All F1 seedlings had levels of infection intermediate between those of Flame and Longbow and no significant maternal effect on the expression of resistance was detected in either the whole seedling or detached leaf tests (data not shown).

Eighty F2 seedlings of the same cross were inoculated with IPO323 in detached leaf tests. There was not a clear distinction between categories of mean disease level (Fig. 1A). It was possible, however, to make a provisional classification of the seedlings' phenotypes by assuming that, if at least one leaf section from an F2 plant was heavily diseased, that individual should have a susceptible genotype; some leaf sections from such a plant might have little or no disease because they were not successfully infected. On the other hand, leaf sections from an individual with a resistant genotype should never be highly diseased. The wheat$M$. graminicola interaction is a difficult disease to work with; therefore, perfect reproducibility between leaves is hard to achieve by any current method (2). For 19 seedlings, the median disease score was $0 \%$ (i.e., three or all four leaf sections had no disease). For 18 of these 19 plants, the maximum level of disease was lower than the maximum on cv. Flame, while the remaining plant had relatively low disease $(10 \%)$. These F2 plants were considered to be resistant. Of seven plants that had two diseased and two undiseased leaf sections, two plants had a maximum disease level lower than that on cv. Flame and also were considered to be resistant, whereas five had higher maximum scores and were considered to be susceptible or to have an intermediate phenotype. The remaining 54 F2 seedlings, with three or four diseased leaf sections, were considered to be susceptible or intermediate. The segregation of 21 resistant to 59 susceptible and intermediate F2 seedlings is consistent with a 1:3 ratio controlled by the segregation of a single gene of intermediate dominance conferring resistance to IPO323 in Flame $\left(\chi^{2}=0.07, P=0.8\right)$.

To test this provisional conclusion, the $\mathrm{F} 2$ seedlings were grown to maturity. F3 families were generated and tested as whole seedlings (Fig. 2). The F3 family scores with IPO323 separated clearly into three nonoverlapping groups (Fig. 1B). Families with low means $(<3 \%)$ and low standard deviations were uniformly resistant while those with high means $(>88 \%)$ and low standard deviations were uniformly susceptible. Families with intermediate
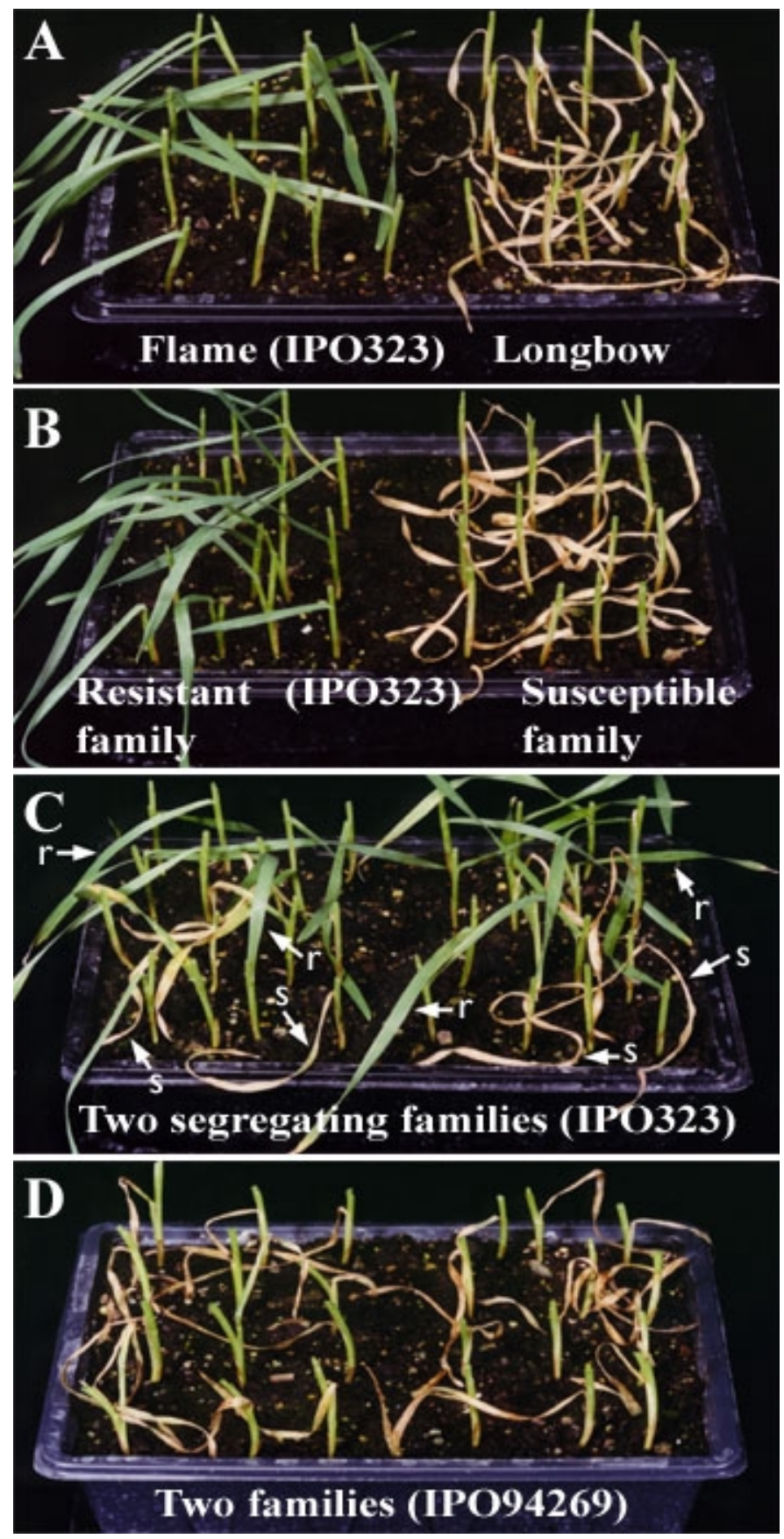

Fig. 2. Responses of Flame $\times$ Longbow F3 families to $M$. graminicola isolates IPO323 and IPO94269. A, Nondiseased Flame seedlings (left) and heavily diseased Longbow seedlings (right), following inoculation with IPO323. B, A homozygous resistant F3 family (left) and a homozygous susceptible F3 family (right) following inoculation with IPO323. C, Two F3 families segregating for Stb6 resistance showing a mixture of seedlings which were healthy (arrows, r) or diseased (arrows, s), following inoculation with IPO323. D, Two F3 families showing nonsegregating susceptibility to IPO94269. All photographs were taken 25 days after inoculation. 
means (between 12 and 79\%) and high standard deviations segregated with resistant, susceptible, and intermediate individuals. These families were presumably homozygous resistant, homozygous susceptible, and segregating, respectively, and were descendants of homozygous resistant, homozygous susceptible, and heterozygous F2 plants. The F3 families were classified as 18 resistant, 44 segregating, and 18 susceptible, which fits closely to the expected 1:2:1 ratio for a single semidominant resistance gene in Flame against IPO323 $\left(\chi^{2}=0.8, P=0.7\right)$. The means of logit-transformed scores for F2 plants and their F3 families were highly correlated ( $r=0.83$; Fig. 1A), implying that the F2 and F3 scores were generally consistent. However, scores for individual F2 plants were less accurate than F3 family mean scores, and 3 of the $21 \mathrm{~F} 2$ plants scored as resistant produced segregating F3 families. These inconsistencies are not surprising because each F2 score was based on only four leaf sections from a single seedling.

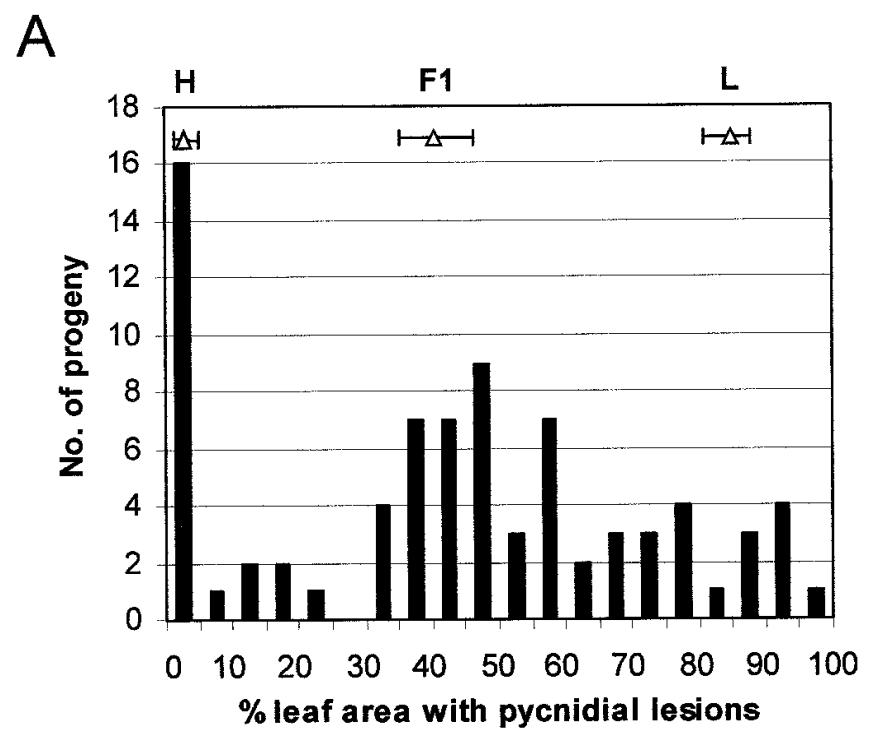

B

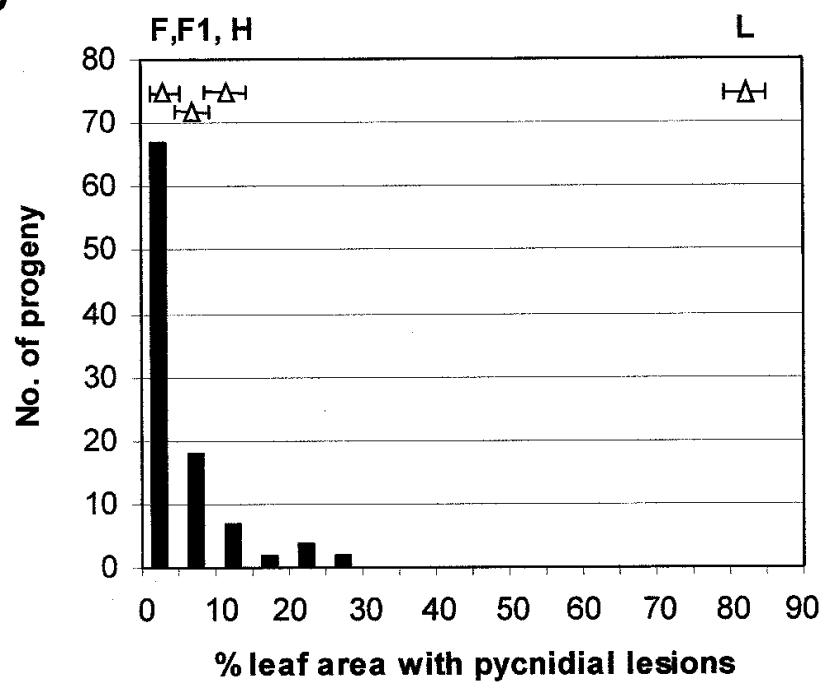

Fig. 3. Segregation of specific resistance to IPO 323 in Hereward $\times$ Longbow and Hereward $\times$ Flame progeny. Histograms showing the frequency distribution of percentage disease levels on F2 individuals of Hereward $(\mathrm{H})$ crossed with A, Longbow (L) and B, Flame (F), inoculated with IPO323. In both $\mathrm{A}$ and $\mathrm{B}$, the mean infection levels of the parental cultivars and the $\mathrm{F} 1$ progeny, tested at the same times as the F2s, are indicated by open triangles. Error bars indicate $95 \%$ confidence intervals for the mean percent disease on the parents and F1s.
All F3 families were uniformly susceptible to IPO94269. Longbow is susceptible to all isolates with which it has been tested, including IPO94269, whereas Flame has moderate partial resistance to this isolate $(2,5)$. Genes controlling partial, possibly isolate-nonspecific resistance were expected to segregate in the F3 generation and therefore to influence disease levels with both IPO323 and IPO94269. Correlations between the mean scores with IPO323 and IPO94269 were investigated within the three classes defined by the segregation of responses to IPO323. There was only a weak correlation between disease levels with the two isolates $(P=0.1$; Fig. 1C), indicating that the IPO323 scores were not significantly affected by the action of any minor genes which controlled responses to IPO94269.

Resistance of Hereward to IPO323. F1 and F2 progeny of the reciprocal crosses between Hereward and Longbow were tested as detached leaves with IPO323. The 12 F1 seedlings tested all showed intermediate levels of infection compared with Hereward and Longbow and there was no evidence of a maternal effect (data not shown). Eighty Hereward $\times$ Longbow F2 seedlings were tested with IPO323 (Fig. 3A). Disease scores were somewhat higher than in the test of the Flame $\times$ Longbow F2, such that relatively few leaf sections had no disease at all. A total of $22 \mathrm{~F} 2$ plants had low mean disease levels $(<25 \%)$, of which 16 had very low levels $(<4 \%)$, within the $95 \%$ confidence interval for Hereward $(1.4 \%)$. Many of the F2s had intermediate means and some had high means, comparable to Longbow (83.7\%). Between 58 and 64 of the F2s therefore had either intermediate or susceptible phenotypes. Whether the six plants which could not easily be classified (scores between 5\% and 24\%) are homozygous resistant or heterozygous, the segregation of resistant to intermediate and susceptible plants fits a $1: 3$ ratio well $\left(\chi^{2}\right.$ test; $P=0.3$ for $16: 64$, $P=0.6$ for 22:58). This is consistent with a single, semidominant gene in Hereward for resistance to IPO323, as in Flame. More complex genetic models involving two or more genes may also fit the data, but cannot be distinguished from the single-gene model with F2 or even F3 data alone.

To test allelism of the resistance genes in cvs. Hereward and Flame, F1 and F2 progeny of reciprocal crosses between these cultivars were tested with IPO323 as detached leaves. All 10 F1 seedlings were resistant to IPO323, with disease levels similar to those of Hereward and Flame; there was no evidence of the semidominance previously observed in F1s of Hereward $\times$ Longbow and Flame $\times$ Longbow. In all, $100 \mathrm{~F} 2$ progeny were tested in two separate experiments (50 progeny per experiment) that were combined for analysis. Disease scores on the parental cultivars were somewhat higher than those in the tests of the F2s of both crosses involving cv. Longbow (compare Fig. 3B with Figs. 1A and $3 \mathrm{~A}$ for Flame $\times$ Longbow and Hereward $\times$ Longbow, respectively). All 100 Hereward $\times$ Flame F2 plants had low disease scores, whereas Longbow had high levels of infection as expected (Fig. 3B). Fourteen F2 plants had higher disease scores than those of the more susceptible parent, Hereward $(10.7 \%)$. However, the logits of the mean scores fitted a normal distribution and in no case did the mean score approach that of Longbow (82.2\%). Susceptible F2 plants would have been detected as upper-tail outliers from the normal distribution. The existence of F2 plants with higher mean scores than Hereward probably indicates that minor genes controlling partial resistance, as well as the single, major gene controlling resistance to IPO323, segregated in this cross. The failure to detect either F1s with intermediate infection levels or susceptible F2 recombinants indicated that the resistance genes in Hereward and Flame are either the same or alleles at the same locus or closely linked to one another.

Tests of the IPO323 $\times$ IPO94269 F1 mapping population. To test whether resistance to IPO323 in Flame and Hereward conforms to a gene-for-gene relationship, we investigated the segregation of virulence and avirulence in a subset of 59 progeny isolates of the $M$. graminicola F1 mapping population derived 
from a cross between isolates IPO323 and IPO94269 (30) on wheat lines with specific resistance to IPO323.

Flame, Shafir, Bezostaya 1, and Longbow were tested as detached leaves with IPO323, IPO94269, and $59 \mathrm{~F} 1$ isolates. The spring wheat cv. Shafir is specifically resistant to IPO323 and was included as a control to compare the detached leaf tests and field tests and to compare the results presented here with those published previously (30). Bezostaya 1 was chosen because its specific resistance to IPO323 is controlled by a gene or genes on chromosome $3 \mathrm{~A}(1)$.

The isolates fell into two distinct classes (Fig. 4A). IPO94269 and 32 progeny were virulent to Shafir, Flame, and Longbow while IPO323 and 27 progeny were virulent to Longbow but avirulent to both Flame and Shafir. This segregation fitted closely to the 1:1 ratio for virulence:avirulence expected for segregation at a single locus ( $\chi^{2}$ test, $P=0.5$ ). The responses of Bezostaya 1 to the 59 isolates were more difficult to interpret. Resistance to IPO323 in Bezostaya 1 was less strongly expressed than in Flame or Shafir, as previously observed in other detached leaf experiments (2), and there was more variation between replicate leaf samples. It appears that avirulence to Bezostaya 1 cosegregates with that of Shafir and Flame, but the classification of progeny was less clear on Bezostaya 1 than on the other two cultivars (Fig. 4B).

In field trials, data were obtained for IPO323, IPO94269, and 57 F1 progeny, including 56 progeny used in the detached leaf tests. All isolates were scored as either virulent or avirulent on all four lines (Shafir, Hereward, Vivant, and NSL92-5719) and the results were consistent between years and replicates. The classification of 56 progeny isolates was completely consistent with that in the detached leaf tests, while the additional isolate was avirulent. The resulting segregation ratio of 28 avirulent to 29 virulent progeny is, again, consistent with segregation at a single locus $\left(\chi^{2}\right.$ test, $\left.P=0.9\right)$.

Map location of $\boldsymbol{S t b 6}$. The results of the progeny isolate tests suggested that all the wheat lines may recognize the same avirulence factor in IPO323 and so may share the same resistance gene. The Flame resistance gene, named Reaction to Mycosphaerella graminicola 6 (Stb6) was, therefore, predicted to be on chromosome 3A, as in Bezostaya 1 (1). Microsatellite markers previously located to chromosome $3 \mathrm{~A}$ (6,37, and P. Stephenson, personal communication) were used to map the resistance gene in cv. Flame. Eight microsatellite markers, PSP3047, WMC11 (maps to locus Xwmc11), WMC60, WMC153, WMC264, WMS32, WMS369 (locus Xgwm369), and WMS391, detected polymorphism between cvs. Flame and Longbow and segregated in the Flame $\times$ Longbow F4 mapping population, which consisted of 27 resistant and 31 susceptible progeny lines. Stb6 mapped close to Xgwm369 in the distal part of the short arm of chromosome 3A (37), with a map distance $(m)$ of $2 \mathrm{cM}$ and a log-likelihood (LOD) of 14.9. Only one recombinant between Xgwm369 and Stb6 was detected. The Longbow and Flame alleles were 189 and $197 \mathrm{bp}$ in size, respectively. Xwmcll, which maps close to the centromere (P. Stephenson, personal communication), was loosely linked to both Stb6 and Xgwm369 $(m=33 \mathrm{cM}$ and LOD $=1.4$ in both cases). These three markers were not linked to the other seven markers (LOD < 0.5). JoinMap's JMMAP32 module placed Stb6 between $\mathrm{Xgwm} 369$ and $\mathrm{Xwmc11}$, but this ordering is tentative and only slightly more likely than Stb6 being distal to Xgwm369.

\section{DISCUSSION}

In this article, the genetics of the specific resistance of wheat cultivars to a single isolate of $M$. graminicola have been analyzed. $\mathrm{Cv}$. Flame carries a single semidominant gene conferring specific resistance to isolate IPO323 which has been named Stb6. In complementary genetic analysis of the pathogen, IPO323 was shown to carry a single gene for specific avirulence on cv. Flame. Given that there is a single gene in the host, likewise the pathogen, and that resistance is expressed when the host and pathogen have matching resistance and avirulence genes, this interaction conforms to the gene-for-gene model of Flor (18). This is the first time that a gene-for-gene interaction between wheat and $M$. graminicola has been tested and demonstrated genetically. Comparatively few gene-for-gene relationships have been proved in this way (44), although many more have been inferred, without proof, from patterns of interaction between host and pathogen genotypes.

Five genes for resistance to Septoria tritici blotch in wheat have been named previously $(3,34)$, of which only $S t b 5$ has been mapped (3). Stb1, Stb2, and Stb3 were identified using field
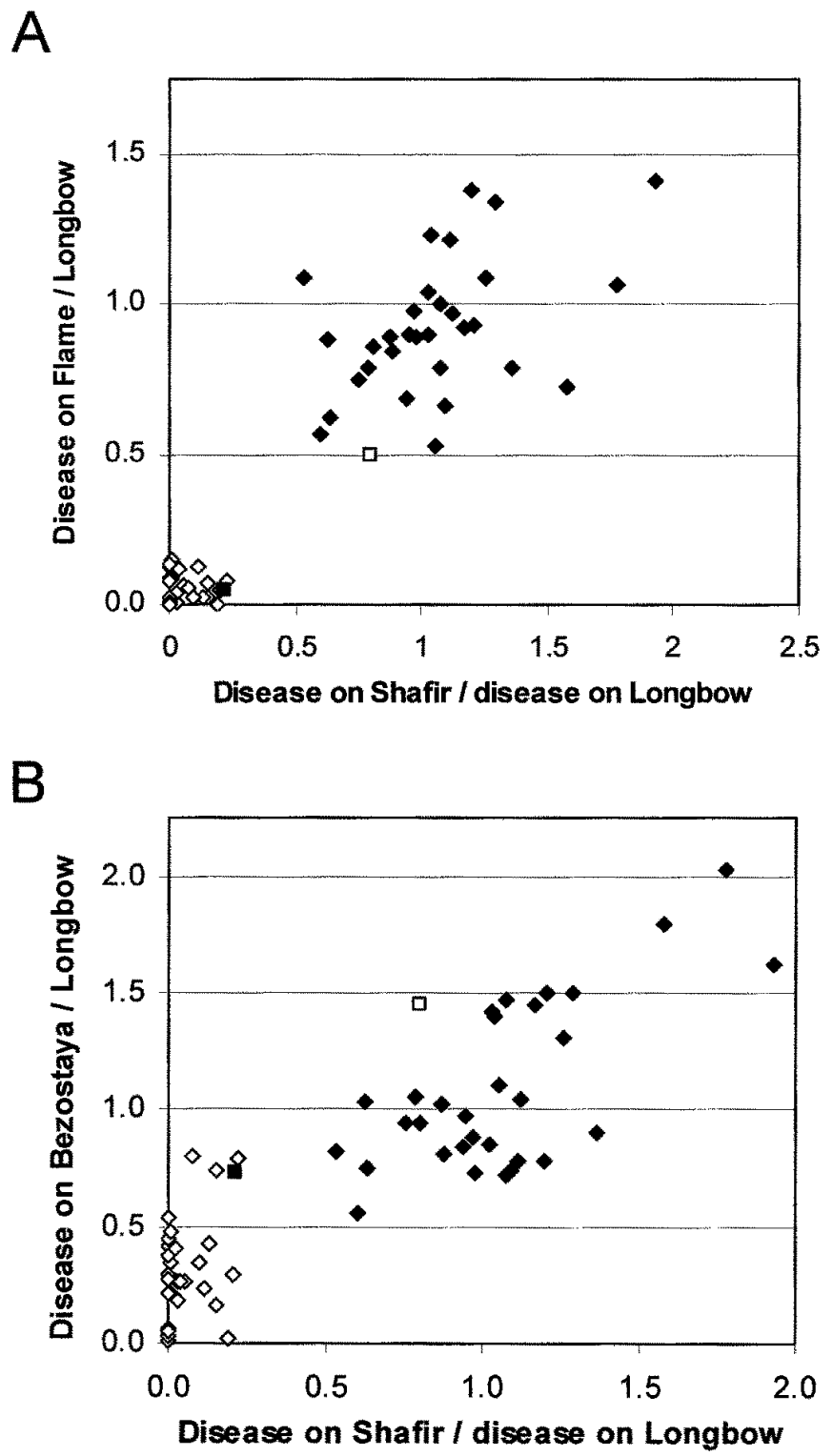

Fig. 4. Segregation of avirulence in IPO323 $\times$ IPO94269 Mycosphaerella graminicola progeny towards Flame, Bezostaya 1, and Shafir in detached leaf tests. A, Mean disease scores on Flame divided by mean disease scores on Longbow plotted against Shafir/Longbow means. B, Bezostaya/Longbow means plotted against Shafir/Longbow means. The graphs demonstrate that the avirulence (open diamonds) or virulence (closed diamonds) of each isolate toward Flame (A) co-segregated with avirulence or virulence towards the control cv. Shafir, while avirulence/virulence to Bezostaya 1 (B) was at least strongly correlated with avirulence/virulence to Shafir. The scores for the parental isolates IPO323 (avirulent; closed square) and IPO94269 (virulent; open square) are shown on each graph. 
populations of M. graminicola (47), whereas Stb4 was identified with a single pathogen isolate (40). It is not known if any of these five genes controls a gene-for-gene interaction.

Several experiments indicated that cvs. Flame and Hereward probably share the same resistance gene, Stb6. First, there were no susceptible recombinants with scores approaching that of the control cv. Longbow among $100 \mathrm{~F} 2$ progeny of Flame $\times$ Hereward, implying that the major genes for resistance to IPO323 in these two cultivars are at least very closely linked to one another. Second, all F1 progeny of the same cross were resistant, demonstrating that the semidominance of each gene had been complemented. Third, in genetic analysis of the pathogen, tests with the F1 progeny of IPO $94269 \times$ IPO323 indicated that the resistance genes of cvs. Flame and Hereward match the same avirulence gene in IPO323 or closely linked avirulence genes. It is unlikely that the two resistance genes would reside at the same locus and recognize the same avirulence product but encode different resistance products. There was transgressive segregation in the F2 generation, with some progeny having higher scores than either parent, but there was a normal distribution of mean scores of the F2 plants. This probably indicates that genes controlling partial resistance also segregated in this cross.

From experiments with the F1 progeny isolates, it appears that genes in Shafir, Vivant, Hereward, Flame, and the breeding line NSL92-5719 recognize the same avirulence gene in IPO323. Bezostaya 1 probably also recognizes this avirulence, but the data were not as clear for this cultivar as for the others. The most likely conclusion is that all these lines carry the same gene, Stb6, for resistance to IPO323. Alternatively, several different resistance genes may recognize products of avirulence genes that are closely linked, as suggested in by Kema et al. (30). For the latter explanation to hold, however, the matching resistance genes in Flame and Hereward must be closely linked, at or near the Stb6 locus, because of the absence of recombination in Flame $\times$ Hereward progeny. Discovering that Flame probably recognizes the same avirulence gene as Bezostaya 1 was informative because of our prior knowledge that chromosome $3 \mathrm{~A}$ is responsible for conferring IPO323 resistance in Bezostaya 1 (1). Location of Stb6 in Flame to its position on chromosome $3 \mathrm{~A}$ was greatly facilitated by this information.

If the Stb6 resistance gene is as widespread in wheat germ plasm as these and other data suggest $(2,5,28,30)$, this discovery has significant implications for wheat breeders. When breeding material is selected for resistance to diseases such as Septoria tritici blotch, it is generally assumed that good sources of resistance with very different pedigrees have different resistance genes. Breeders often seek to combine several such genes in a new cultivar to reduce the rate of evolution of the pathogen population to virulence. This approach is termed gene "stacking" or "pyramiding". If, however, one major resistance gene is present in a large proportion of the available breeding material, breeders may repeatedly select this gene in their material. Wheat breeders usually trial material with mixtures of pathogen isolates rather than single isolates; therefore, they cannot check whether different lines carry different resistance specificities. Stb6 may, therefore, have been selected repeatedly over the course of the history of wheat breeding, even though breeders have used diverse plant material as sources of resistance $(19,45)$.

M. graminicola grows entirely in the leaf apoplast without invading plant cells or forming haustorial connections $(8,13,31)$. In this respect, $M$. graminicola is similar to the tomato leaf mould pathogen Cladosporium fulvum, which also grows only in the apoplast (12). The resistance mechanisms of tomato to $C$. fulvum also show some similarity to those of wheat during specific resistance to $M$. graminicola isolates. The $C f$ resistance genes effective against $C$. fulvum are incompletely dominant (21), as is the Stb6mediated resistance to isolate IPO323 of M. graminicola. In both pathosystems, fungal arrest is achieved without a rapid, substan- tial hypersensitive response (HR) $(8,21,31)$. Furthermore, $M$. graminicola and $C$. fulvum are phylogenetically very closely related fungi $(10,20)$. The $C f$ resistance genes in tomato have been well characterized and are known to recognize $C$. fulvum avirulence products in a gene-for-gene manner. Most cloned resistance genes that are effective against biotrophic fungal pathogens fall into the nucleotide binding site plus leucine-rich repeat (NB-LRR) class (14). The NB-LRR genes are all presumed to be cytoplasmic and recognize ligands delivered into the plant cell (11), although at least one is associated with the plasma membrane (4). The $C f$ genes do not fall into the NB-LRR class; instead, they encode membrane-anchored extra-cytoplasmic LRR proteins that are predicted to recognize avirulence products in the plant apoplast (22). Based on the similarity of M. graminicola and C. fulvum infection processes, their phylogenetic relatedness, and the operation of resistance through semidominant gene-for-gene mechanisms not involving HR (21), we predict that Stb6 is more likely to fall into the extra-cytoplasmic LRR class than the NB-LRR class of resistance genes. To test this hypothesis, it will be necessary to clone Stb6 from wheat and compare its sequence with that of other cloned resistance genes.

The avirulence gene in IPO323 that corresponds to Stb6 has been mapped using amplified fragment length polymorphism (AFLP) markers and is in the process of being cloned (30). The isolation of Stb6 from Flame would, therefore, allow both partners of this gene-for-gene interaction to be analyzed together. There are very few plant-pathogen interactions where both the resistance gene and its corresponding avirulence gene have been cloned. Only one such pair has been isolated in a fungal disease of cereals, rice blast $(7,35)$, in which the resistance gene, $P i$-ta, falls into the NB-LRR class. The only other matching gene pairs currently cloned from plant-fungus interactions are those of the tomato resistance genes $C f-9$ and $C f-4(24,43)$ and their avirulence counterparts Avr-9 and Avr-4 from C. fulvum $(25,38)$. For the $C f$ genes, access to both interacting partners has provided valuable tools for dissection of the defense responses and, in the case of $C f-9 / A v r 9$, has contributed to potential new genetic engineering strategies for plant disease resistance (33). Little is currently known about the mechanisms of Septoria tritici blotch resistance in wheat; therefore, access to the sequences of both Stb6 and its matching Avr gene would doubtless be of value for increasing our understanding of specific resistance to this important disease.

\section{ACKNOWLEDGMENTS}

This research was supported by the EU Framework 4 Biotechnology programme, the Ministry of Agriculture, Nature Management and Fisheries of The Netherlands and the Department of Environment, Food and Rural Affairs for England. We thank Syngenta Seeds for providing the Flame $\times$ Longbow crosses; M. Todorova, S. Verhaegh, and the field staff of Plant Research International for assisting with field experiments; P. Stephenson and J. Kirby for provision of the microsatellite primers; and L. Arraiano and members of the Wageningen Mycosphaerella group for critically reading the paper.

\section{LITERATURE CITED}

1. Arraiano, L. S. 2001. Genetics of resistance of wheat to Septoria tritici blotch. Ph.D. thesis. University of East Anglia, UK.

2. Arraiano, L. S., Brading, P. A., and Brown, J. K. M. 2001. A detached seedling leaf technique to study resistance to Mycosphaerella graminicola (anamorph Septoria tritici) in wheat. Plant Pathol. 50:339-346.

3. Arraiano, L. S., Worland, A. J., Ellerbrook, C., and Brown, J. K. M. 2001. Chromosomal location of a gene for resistance to Septoria tritici blotch (Mycosphaerella graminicola) in the hexaploid wheat 'Synthetic 6x'. Theor. Appl. Genet. 103:758-764.

4. Boyes, D. C., Nam, J., and Dangl, J. L. 1998. The Arabidopsis thaliana RPM1 disease resistance gene product is a peripheral plasma membrane protein that is degraded coincident with the hypersensitive response. Proc. Natl. Acad. Sci. USA 95:15849-15854.

5. Brown, J. K. M., Kema, G. H. J., Forrer, H.-R., Verstappen, E. C. P., 
Arraiano, L. S., Brading, P. A., Foster, E. M., Fried, P. M., and Jenny, E. 2001. Resistance of wheat varieties to Septoria tritici blotch caused by isolates of Mycosphaerella graminicola in field trials. Plant Pathol. 50:325-338.

6. Bryan, G. J., Collins, A. J., Stephenson, P., Orry, A., Smith, J. B., and Gale, M. D. 1997. Isolation and characterization of microsatellites from hexaploid bread wheat. Theor. Appl. Genet. 94:557-563.

7. Bryan, G. T., Wu, K. S., Farrall, L., Jia, Y. L., Hershey, H. P., McAdams, S. A., Faulk, K. N., Donaldson, G. K., Tarchini, R., and Valent, B. 2000. A single amino acid difference distinguishes resistant and susceptible alleles of the rice blast resistance gene Pi-ta. Plant Cell 12:2033-2045.

8. Cohen, L., and Eyal, Z. 1993. The histology of processes associated with the infection of resistant and susceptible wheat cultivars with Septoria tritici. Plant Pathol. 42:737-743.

9. Cowger, C., Hoffer, M. E., and Mundt, C. C. 2000. Specific adaptation by Mycosphaerella graminicola to a vertically resistant wheat cultivar. Plant Pathol. 49:445-451.

10. Cunfer, B. M., and Ueng, P. P. 1999. Taxonomy and identification of Septoria and Stagonospora species on small-grain cereals. Annu. Rev. Phytopathol. 37:267-284.

11. Dangl, J. L., and Jones, J. D. G. 2001. Plant pathogens and integrated defense responses to infection. Nature 411:826-833.

12. De Wit, P. J. G. M. 1977. A light and scanning-electron microscope study of infection of tomato plants by virulent and avirulent races of Cladosporium fulvum. Neth. J. Plant. Pathol. 83:109-122.

13. Duncan, K. E., and Howard, R. J. 2000. Cytological analysis of wheat infection by the leaf blotch pathogen Mycosphaerella graminicola. Mycol. Res. 104:1074-1082.

14. Ellis, J., Dodds, P., and Pryor, T. 2000. Structure, function and evolution of plant disease resistance genes. Curr. Opin. Plant Biol. 3:278-284.

15. Eyal, Z. 1999. Breeding for resistance to Septoria and Stagonospora diseases. Pages 332-344 in: Septoria of Cereals, A Study of Pathosystems. J. A. Lucas, P. Bowyer, and H. M. Anderson, eds. CAB International, Wallingford, UK.

16. Eyal, Z., Amiri, Z., and Wahl, I. 1973. Physiologic specialization of Septoria tritici. Phytopathology 63:1087-1091.

17. Eyal, Z., Scharen, A. L., Prescott, J. M., and van Ginkel, M. 1987. The Septoria diseases of wheat: Concepts and methods of disease management. CIMMYT, Mexico, DF.

18. Flor, H. H. 1971. Current status of the gene-for-gene concept. Annu. Rev. Phytopathol. 9:275-296.

19. Gilchrist, L., Gomez, B., Gonzalez, R., Fuentes, S., Mujeeb-Kazi, A., Pfeiffer, W., Rajaram, S., Rodriguez, R., Skovmand, B., van Ginkel, M., and Velazquez, C. 1999. Septoria tritici resistance sources and breeding progress at CIMMYT, 1970-99. Pages 134-139 in: Septoria and Stagonospora Diseases of Cereals: A Compilation of Global Research. M. van Ginkel, A. McNab, and J. Krupinsky, eds. CIMMYT, Mexico, DF.

20. Goodwin, S. B., Dunkle, L. D., and Zismann, V. L. 2001. Phylogenetic analysis of Cercospora and Mycosphaerella based on the internal transcribed spacer region of ribosomal DNA. Phytopathology 91: 648-658.

21. Hammond-Kosack, K. E., and Jones, J. D. G. 1994. Incomplete dominance of tomato $C f$ genes for resistance to Cladosporium fulvum. Mol. Plant-Microbe Interact. 7:58-70.

22. Hammond-Kosack, K. E., and Jones, J. D. G. 1997. Plant disease resistance genes. Annu. Rev. Plant Physiol. Plant Mol. Biol. 48:575-607.

23. Johnson, R. 1992. Past, present and future opportunities in breeding for disease resistance, with examples from wheat. Euphytica 63:3-22.

24. Jones, D. A., Thomas, C. M., Hammond-Kosack, K. E., Balint-Kurti, P. J., and Jones, J. D. G. 1994. Isolation of the tomato Cf-9 gene for resistance to Cladosporium fulvum by transposon tagging. Science 266:789-793.

25. Joosten, M. H. A. J., Cozijnsen, T. J., and De Wit, P. J. G. M. 1994. Host resistance to a fungal tomato pathogen lost by a single base-pair change in an avirulence gene. Nature 367:384-386.

26. Kema, G. H. J., Annone, J. H., Sayoud, R. S., Van Silfhout, C. H., Van Ginkel, M., and de Bree, J. 1996. Genetic variation for virulence and resistance in the wheat-Mycosphaerella graminicola pathosystem. I. Interactions between pathogen isolates and wheat cultivars. Phyto- pathology 86:200-212.

27. Kema, G. H. J., Sayoud, R., Annone, J. G., and Van Silfhout, C. H., 1996. Genetic variation for virulence and resistance in the wheat-Mycosphaerella graminicola pathosystem. II. Analysis of interactions between pathogen isolates and host cultivars. Phytopathology 86:213-220.

28. Kema, G. H. J., and van Silfhout, C. H. 1997. Genetic variation for virulence and resistance in the wheat-Mycosphaerella graminicola pathosystem. III. Comparative seedling and adult plant experiments. Phytopathology 87:266-272.

29. Kema, G. H. J., Verstappen, E. C. P., Todorova, M., and Waalwijk, C. 1996. Successful crosses and molecular tetrad and progeny analyses demonstrate heterothallism in Mycosphaerella graminicola. Curr. Genet. 30:251-258

30. Kema, G. H. J., Verstappen, E. C. P., and Waalwijk, C. 2000. Avirulence in the wheat Septoria tritici leaf blotch fungus Mycosphaerella graminicola is controlled by a single locus. Mol. Plant-Microbe Interact. 13:1375-1379.

31. Kema, G. H. J., Yu, D., Rijkenberg, F. H. J., Shaw, M. W., and Baayen, R. P. 1996. Histology of the pathogenesis of Mycosphaerella graminicola in wheat. Phytopathology 86:777-786.

32. Kosambi, D. D. 1944. The estimation of map distances from recombination values. Ann. Eugen. 12:172-175.

33. Laugé, R., and De Wit, P. J. G. M. 1998. Fungal avirulence genes: Structure and possible functions. Fungal Genet. Biol. 24:285-297.

34. McIntosh, R. A., Hart, G. E., Devos, K. M., Gale, M. D., and Rogers, W. J. 1998. Catalogue of gene symbols of wheat. Page 129 in: Proc. 9th Int. Wheat Genet. Symp. Vol. 5. Univ. Ext. Press, University of Saskatchewan, Saskatoon, Canada.

35. Orbach, M. J., Farrall, L., Sweigard, J. A., Chumley, F. G., and Valent, B. 2000. A telomeric avirulence gene determines efficacy for the rice blast resistance gene Pi-ta. Plant Cell 12:2019-2032.

36. Polley, R. W., and Thomas, M. R. 1991. Surveys of diseases of winter wheat in England and Wales 1976-88. Ann. Appl. Biol. 119:1-20.

37. Röder, M. S., Korzun, V., Wendehake, K., Plaschke, J., Tixier, M.-H., Leroy, P., and Ganal, M. W. 1998. A microsatellite map of wheat. Genetics 149:2007-2023.

38. Schottens-Toma, I. M. J., and De Wit, P. J. G. M. 1988. Purification and primary structure of a necrosis-inducing peptide from the apoplastic fluids of tomato infected with Cladosporium fulvum (syn. Fulvia fulva). Physiol. Mol. Plant Pathol. 33:59-67.

39. Shaner, G., and Finney, R. E. 1977. The effect of nitrogen fertilization on the expression of slow mildewing resistance in Knox wheat. Phytopathology 67:1051-1056.

40. Somasco, O. A., Qualset, C. O., and Gilchrist, D. G. 1996. Single-gene resistance to Septoria tritici blotch in the spring wheat cultivar 'Tadinia'. Plant Breed. 115:261-267

41. Stam, P., and van Ooijen, J. W. 1995. JoinMap version 2.0: Software for the Calculation of Genetic Linkage Maps. CPRO-DLO, Wageningen, the Netherlands.

42. Stewart, C. N., and Via, L. E. 1993. A rapid CTAB DNA isolation technique useful for RAPD fingerprinting and other PCR applications. Biotechniques 14:748-750.

43. Thomas, C. M., Jones, D. A., Parniske, M., Harrison, K., Balint-Kurti, P. J., Hatzixanthis, K., and Jones, J. D. G. 1997. Characterization of the tomato $C f-4$ gene for resistance to Cladosporium fulvum identifies sequences that determine recognitional specificity in Cf-4 and Cf-9. Plant Cell 9:2209-2204

44. Thompson, J. N., and Burdon J. J. 1992. Gene-for-gene coevolution between plants and parasites. Nature 360:121-125.

45. Van Ginkel, M., and Rajaram, S. 1999. Breeding for resistance to the Septoria/Stagonospora blights of wheat. Pages 117-126 in: Septoria and Stagonospora Diseases of Cereals: A Compilation of Global Research. M. van Ginkel, A. McNab, and J. Krupinsky, eds. CIMMYT, Mexico.

46. Welham, S. J. 2000. GLMM. Pages 181-186 in: Genstat Release 4.2 Reference Manual. Part 3: Procedure Library PL12. R. W. Payne and G. M. Arnold, eds. VSN International, Oxford, UK.

47. Wilson, R. E. 1985. Inheritance of resistance to Septoria tritici in wheat. Pages 33-35 in: Septoria of Cereals: Proc. Workshop. A. L. Scharen, ed. Montana State University, Bozeman. 